\title{
Everolimus-eluting coronary stents
}

This article was published in the following Dove Press journal:

Medical Devices: Evidence and Research

10 September 2010

Number of times this article has been viewed

\section{Alejandro Saez \\ Raul Moreno \\ Division of Interventional Cardiology, University Hospital La Paz, Madrid, Spain}

\begin{abstract}
Bare metal stents enabled a reduction in the risk of early procedural complications and restenosis in comparison with balloon angioplasty alone, but introduced a new and devicespecific iatrogenic condition, ie, in-stent restenosis due to increased neointimal hyperplasia. Sirolimus- and paclitaxel-eluting stents reduce restenosis and the need for new revascularizations in comparison with bare metal stents, although at the cost of a slight increase in the risk of late stent thrombosis and a need for prolonged dual antiplatelet therapy. Everolimus is an analog of sirolimus with an increased solubility. In this review, the currently available evidence for everolimus-eluting stents is revised, including randomized trials against bare metal stents, and head-to-head trials comparing this stent with other drug-eluting stents.
\end{abstract}

Keywords: coronary stents, restenosis, everolimus, review

\section{Introduction}

Minimally invasive coronary revascularization by percutaneous transluminal coronary angioplasty was introduced in the late 1970s for the management of symptoms of coronary artery disease. This technology later expanded its indications by also including unstable coronary artery disease. However, percutaneous transluminal balloon coronary angioplasty alone was fraught with problems, including a major risk of abrupt early closure, late restenosis due to elastic recoil, constrictive remodeling, and intimal hyperplasia. The development of the bare-metal stent (BMS) enabled a reduction in the risk of early procedural complications, abrupt closure, and restenosis. However, the BMS introduced a new and device-specific iatrogenic condition, ie, in-stent restenosis, causing late loss, mainly due to excessive neointimal proliferation within the stented segment. Coronary stents virtually eliminate elastic recoil and negative remodeling, but promote neointimal hyperplasia. ${ }^{1}$

In-stent restenosis due to neointimal formation is the main limitation of the BMS, and frequently leads to a subsequent revascularization procedure. By inhibiting neointimal hyperplasia, the drug-eluting stent (DES) dramatically reduces angiographic restenosis and the need for new revascularization, without increasing the risk of stent thrombosis during the first year and need for prolonged dual antiplatelet therapy. ${ }^{2}$

Cypher $^{\circledR}$ and Taxus ${ }^{\circledR}$ stents have been demonstrated to achieve a dramatic reduction in the rate of angiographic restenosis and the need for new revascularization procedures in a variety of clinical and angiographic scenarios. However, the possibility of a slight increase in risk of very late ( $>1$ year after implantation) stent thrombosis, as well as the necessity of long-term dual antiplatelet therapy, has limited the use of these devices and are used in up to two-thirds of procedures. Another problem with the first- 
generation DES is that the stainless steel stent platform may make it difficult to use these devices in very complex lesions (eg, severe tortuosity and calcified lesions). These limitations have led to the development of second-generation DES, which has included more flexible stent platforms, different drugs, and/or different polymers.

Rapamycin (sirolimus), a macrolide immunosuppressant inhibitor of m-TOR (mammalian target of rapamycin), inhibits growth factor-dependent proliferation of hematopoietic and nonhematopoietic cells (vascular smooth muscle cells and fibroblasts) via cell-cycle arrest in the late G1 phase. Rapamycin has been shown to inhibit vascular smooth muscle cell proliferation and migration in vitro and inhibit neointimal growth in balloon-injured rat carotid and porcine coronary arteries. ${ }^{3}$

There are six limus family-related drugs that have been studied in DES, ie, sirolimus, everolimus, biolimus, zotarolimus, tacrolimus, and pimecrolimus. Sirolimus, everolimus, biolimus, and zotarolimus bind to the FKBP 12-binding protein and have a similar effect, but tacrolimus and pimecrolimus bind to the FKBP 506 complex. ${ }^{4}$ In this review, the clinical evidence for the everolimus-eluting coronary stent (EES) is revised.

\section{Components of the everolimus- eluting stent}

Like the other DES, the EES has three components, ie, the antiproliferative drug everolimus, a stent platform, and a release system, ie, the polymer. Everolimus (Certican ${ }^{\circledR}$; Novartis, Basel, Switzerland) is an analog of sirolimus (a second derivate of the limus family with a single minimal alteration in the hydroxyl in position 40 of the molecular structure, alkalinized with a 2-hydroxyethyl group, without chemical modification) resulting in increased solubility in several organic solvents and galenic excipients, and it has been useful in the prevention of allograft rejection after organ transplantation. ${ }^{1,4,5}$ The everolimus-FKB12 complex interferes with FKB12-rapamycin associated protein, a regulatory protein that controls cell metabolism and proliferation through the phosphorylation of p70 S6 kinase and 4E-BP1. Consequently, FKB12-rapamycin associated protein inhibition arrests the cell cycle at the late G1 stage. Everolimus absorbs into local tissue rapidly and possesses longer cellular residence time and activity. In vitro studies have shown that the immunosuppressive activity of everolimus is two- to fivefold lower than that of sirolimus. ${ }^{1,5,6}$

Oral everolimus 0.75 or $1.5 \mathrm{mg}$ is given twice daily for immunosuppression after renal or cardiac transplantation.
Other studies have demonstrated that the immunosuppressive efficacy and incidence of adverse effects for everolimus are correlated with blood concentration. The adverse event profile of everolimus includes hypercholesterolemia, anemia, thrombocytopenia, leucopenia, infections, and renal, gastrointestinal, and neurologic disorders. ${ }^{7}$ However, everolimus is almost always undetectable in blood 30 days after EES implantation. Wiemer et al showed in a pharmacokinetic study that only when a patient received the maximum of four stents was it possible to achieve a drug concentration similar to that with oral treatment within a short period after stent implantation, with a maximal concentration of $2.79 \mathrm{ng} / \mathrm{mL} .^{7}$ For most patients, whole blood concentration initially increased to reach a maximum at about 10-60 minutes after stent implantation. Thereafter, whole blood concentration decreased biphasically, with an initially fast distribution/ elimination phase followed by a slower elimination phase. The biphasic distribution is the result of initial distribution to the tissues and subsequent elimination from blood. Because blood concentrations increase rapidly after stent placement, the initial release of everolimus from the stent must be higher than the net drug distribution to tissues and its clearance from blood. At peak concentration, release of drug from the stent equals its distribution to the tissues and clearance from the blood. After the peak, clearance of everolimus from blood is higher than its release from the stent, and everolimus concentration decreases. Apparently the high release from the stent is only temporary because no steady-state or plateau concentration is observed. ${ }^{7}$

Different coronary stents have been developed containing everolimus as an antiproliferative agent. The platform of the Xience V (Promus ${ }^{\circledR}$ ) stent, the most widely studied and used EES, is a L-605 cobalt chromium expandable balloon stent remarkably similar to its BMS equivalent, the Multi-Link Vision $\left.^{\circledR}\right)$, the main characteristics of which are low strut thickness $(81 \mu \mathrm{m})$, high flexibility and deliverability, an acceptable compliance, recoil, and risk of plaque prolapse, and overall good radio-opacity. ${ }^{1}$ The polymer coating of $\mathrm{Xience} \mathrm{V}$ is formed by two layers, ie, a thin primer adhesion layer of poly(n-butyl methacrylate) and a drug reservoir of poly(vinylidene fluoride-co-hexafluoropropylene). The layer of everolimus-polymer matrix is applied to the surface of the stent and loaded with $100 \mu \mathrm{g}$ of everolimus per centimeter of stent surface area with no top-coat polymer layer. Eighty percent of the stent drug is released during the first month, and all the drug is released within four months. The coating thickness is lower for the Xience $\mathrm{V}(5.3 \mu \mathrm{m})$ than for the Cypher $(7.2 \mu \mathrm{m})$ or Taxus $(15.6 \mu \mathrm{m})$ stents. $^{1,5}$ 
In the FUTURE (First Use To Underscore Restenosis reduction with Everolimus) I and FUTURE II trials, the EES platform was the S-Stent manufactured by Biosensors (Newport Beach, CA). This is a stainless steel, tubular stent, with everolimus coated onto the S-Stent with a bioabsorbable poly-l-lactic acid polymer) in a 1:1 ratio, with approximately $70 \%$ of drug release in 30 days and $85 \%$ in 90 days.

More recently, the Promus element stent has been developed, with a novel stent platform made of a platinum alloy with thin struts $(81 \mu \mathrm{m})$, and using fluorinated copolymer (vinylidene fluoride-co-hexafluoropropylene) as a permanent polymer.

Finally, the bioabsorbable everolimus-eluting stent (BVS) is composed of a poly-1-lactic acid backbone, coated with a bioabsorbable polymer containing everolimus, and expected to be totally metabolized and absorbed in the human body.

\section{Everolimus-eluting versus bare metal stents}

The EES has been shown to decrease neointimal proliferation significantly at six months compared with the BMS in the FUTURE I and FUTURE II trials. In the single-center FUTURE I trial, 42 patients were randomized in a 2:1 ratio to the EES or the BMS. After the FUTURE I trial, the subsequent multicenter FUTURE II enrolled 64 patients, using a reverse randomization scheme (1:2 ratio for EES versus $\mathrm{BMS}$, respectively) to equalize the EES and BMS arms when the two studies were combined. Inclusion and exclusion criteria for the two studies were identical except for the inclusion of diabetic patients in FUTURE II. All patients received aspirin $325 \mathrm{mg} /$ day and a clopidogrel $300 \mathrm{mg}$ loading dose immediately and after $75 \mathrm{mg}$ /day for six months. At six-month follow up, EES in-stent late lumen loss decreased by $78 \%-94 \%$, resulting in a significant $34 \%-42 \%$ increase in minimum lumen area compared with the BMS across all vessel sizes as assessed by intravascular ultrasound. There were no cases of in-stent restenosis with the EES at any vessel size but eight cases with the BMS (five in small vessels). No stent thrombosis, aneurysm formation, or incomplete late stent apposition was observed in any group. The EES appears to be effective for treatment of de novo coronary lesions in decreasing neointimal proliferation at six-month follow-up compared with the BMS, regardless of vessel size. ${ }^{1,8}$

The SPIRIT I trial was a single-blind randomized trial performed in nine centers. The inclusion criteria were stable or unstable coronary disease, with the exclusion of overt myocardial infarction, plus the presence of a single de novo coronary lesion $3.0 \mathrm{~mm}$ in diameter as assessed by quantitative coronary angiography, that could be covered by an $18 \mathrm{~mm}$ stent. Notably, no patient with unprotected left main, chronic total occlusion, bifurcation lesion, or in-stent restenosis could be included. Patients were thus randomized to the Xience $\mathrm{V}$ stent versus a matching Multi-Link Vision stent. A single stent, $3.0 \mathrm{~mm}$ in diameter, $18 \mathrm{~mm}$ long, was used in the study. Dual antiplatelet therapy was recommended for three months postprocedure. Follow-up was by clinical assessment, quantitative coronary angiography, and intravascular ultrasound at six months. The study randomized 28 patient to the EES, and 32 to the BMS. The primary endpoint was angiographic in-stent luminal late loss, which was $0.10 \mathrm{~mm}$ for the EES and $0.87 \mathrm{~mm}$ for the BMS $(P<0.01)$. Binary angiographic restenosis ( $>50 \%$ stenosis at follow-up) was detected in $0 \%$ and $25.9 \%$ of patients allocated to the EES and BMS, respectively $(P<0.01)$. Intravascular ultrasound consistently observed a significant reduction in neointimal hyperplasia with the EES. Concerning clinical efficacy, the SPIRIT I trial suggested beneficial effects of the Xience V stent in terms of target vessel failure $(3.8 \%$ versus $21.4 \%, P=0.102) .{ }^{2}$ In the two year follow-up results of SPIRIT FIRST, in-stent late loss was $0.10 \pm 0.23 \mathrm{~mm}$ for the EES versus $0.84 \pm 0.36 \mathrm{~mm}$ for the BMS $(P<0.01)$. No major device-related adverse cardiac events were reported, and there was no stent thrombosis with either the EES or the BMS over two years.

Data from these trials comparing the EES and BMS show that the EES has among the lowest in-stent late loss values. This is of great clinical importance, since in-stent late loss is related with the clinical benefit of a given DES, without comprising safety.

In the ABSORB study, the safety and efficacy of the BVS was assessed in 30 patients undergoing intervention for native coronary artery stenosis. This stent is made of poly-1-lactic acid that provides support and has a coating of poly (D,L-lactic acid) that serves as a reservoir of everolimus. The composite endpoint of this study was cardiac death, myocardial infarction, and ischemia-driven target lesion revascularization. The procedure was successful in all patients, while device success was 94\%. The stent became dislodged in two patients, and in one the site was treated with a Cypher stent, whereas in the other a new BVS stent was deployed. One patient had a non-Q wave infarction in association with a revascularization procedure. There were no other complications, and no deaths or stent thromboses were observed. Binary restenosis at six months developed in three patients (12\%). Angiographic in-stent late loss at six months was $0.44(0.35)$ $\mathrm{mm}$ and was mainly due to a mild reduction of the stent 
area $(-11.8 \%)$, as measured by intravascular ultrasound. ${ }^{9}$ At two years, the device was safe, with no cardiac deaths, ischemia-driven target lesion revascularizations, or stent thromboses recorded, and only one myocardial infarction (non-Q wave). At two years, in-stent late loss was $0.48 \pm 0.28 \mathrm{~mm} .{ }^{10}$ The investigators detected transient but long-term effective scaffolding of the vessel, device bioabsorption, complete strut apposition, potential late lumen enlargement associated with decreased plaque burden, and restoration of normal vasomotion. Clinicians should note that the lesions treated in this study represent only the simplest seen in current clinical practice, and the radial strength of this stent will require further testing in more complex lesions. The findings of this preliminary report need to be confirmed in larger prospective studies, but bioabsorbable stents may indeed be unique for treatment of flow-limiting plaque, by not only eliminating the obstruction, but also restoring vascular integrity. ${ }^{11}$

\section{Everolimus-eluting versus other drug-eluting stents}

There have been some trials comparing the Xience V stent with other DES types, mainly with the Taxus stent. In the SPIRIT II trial, 300 patients in Europe and the Asia Pacific region were randomized $3: 1$ to the Xience $V(n=223)$ or Taxus $(n=77)$. Inclusion criteria were a maximum of two lesions with a diameter between 2.5 and $3.75 \mathrm{~mm}$ and length $<28 \mathrm{~mm}$. The primary endpoint was six-month in-stent late loss of 0.12 for the EES and 0.37 for the Taxus $(P<0.001)$. Binary restenosis was detected in $1.3 \%$ versus $3.5 \%$, respectively $(P=0.194)$, and target lesion revascularization in $2.7 \%$ versus $6.5 \%(P=0.157)$, and stent thrombosis occurred in $0.5 \%$ versus $1.3 \%(P=0.448)$ for the EES and Taxus, respectively. ${ }^{1,12,13}$

The SPIRIT III trial recruited patients with similar features to those enrolled in SPIRIT II, and was a prospective, multicenter, randomized, single-blind, controlled clinical trial done at 65 US and 12 Japanese sites. A total of 1002 patients with either one or two de novo native coronary artery lesions were randomized in a 2:1 ratio to the EES $(n=669)$ or Taxus $(n=333)$. Dual antiplatelet therapy was continued for six months. The primary endpoint was six-month in-segment late loss, which was significantly lower in EES patients $(0.14 \pm 0.41$ versus $0.28 \pm 0.48 \mathrm{~mm}, P<0.001)$. In-stent late loss $(0.16 \pm 0.41$ versus $0.30 \pm 0.53 \mathrm{~mm}, P<0.001)$, and the rate of binary angiographic restenosis $(2.3 \%$ versus $5.7 \%, P=0.083$ ) were also lower with the EES. The hazard curves for events between one and two years continued to diverge, and at the end of two years of follow-up, patients treated with the EES had a significant $32 \%$ reduction in target vessel failure rate and a $45 \%$ reduction in major adverse cardiac events. ${ }^{1,17}$

More recently, two larger studies comparing the EES and the Taxus stent have been presented, both of them with the same clinical endpoints, ie, target lesion failure at one year for SPIRIT IV and major adverse cardiac events at one year in the COMPARE trial. The number of patients included was 3687 in SPIRIT IV (2:1 randomization) and 1800 in COMPARE (1:1 randomization). In SPIRIT IV, target lesion failure at one year occurred in $3.9 \%$ versus $6.6 \%$ for the EES and Taxus, respectively $(P<0.01)$. In COMPARE, the rate of major cardiac events at one year was $6.2 \%$ versus $0.1 \%$ for the EES and Taxus, respectively $(P<0.01)$. Importantly, the rate of stent thrombosis was significantly lower for the EES in both trials $(0.2 \%$ versus $0.8 \%, P<0.01$, in SPIRIT IV, and $0.7 \%$ versus $2.6 \%$, $P<0.01$, in COMPARE). In both trials, this reduction in the one-year rate of stent thrombosis was mainly due to a reduction in the incidence of thrombosis in the first month after stent implantation. Although this may be partly explained by differences in the stent platform between both types of DES, it remains speculative. ${ }^{1,14-16}$

Another recently presented trial is the randomized ISARTEST-4 (The Intracoronary Stenting and Angiographic Results: Test Efficacy of 3 Limus-Eluting STents-4) study. A substudy of this trial compared EES $(n=652)$ with the sirolimus-eluting Cypher coronary stent $(n=652)$. The primary endpoint was the incidence of major cardiac events at one year, which was $13.6 \%$ and $15.2 \%$ for the EES and Cypher, respectively $(P=0.46) \cdot{ }^{17}$

The results of these head-to-head trials evaluating the efficacy of the EES demonstrates that the EES is superior to the Taxus in terms of angiographic (in-stent late loss, binary angiographic restenosis), and clinical (revascularization, cardiac events) outcomes. There are few data comparing the EES and Cypher stents. The only trial comparing both of these DES have no data showing superiority or inferiority of either type of stent.

Apart from these trials, there are also a number of randomized studies that are currently ongoing. The SPIRIT V study is a prospective, open-label, single-arm registry evaluating the performance of the Xience V stent in real life. Within this study, there is a randomized substudy of 300 diabetic patients who are being randomized to the EES or 
Taxus stent (2:1 design), with in-stent late loss at nine months as the primary endpoint. ${ }^{1}$ The SPIRIT WOMEN is a registry for the Xience $\mathrm{V}$ coronary stent in female patients that also includes a randomized substudy comparing the EES and Taxus stent. ${ }^{18}$

The EXCELLENT (Efficacy of Xience/Promus versus Cypher in reducing Late Loss after stENTing) trial is a prospective, randomized, open-label, $2 \times 2$ factorial-designed multicenter trial testing whether the EES is noninferior to the sirolimus-eluting stent (3:1 randomization) in reducing late loss at nine months and to test whether a six-month duration of dual antiplatelet therapy is noninferior to a 12-month duration of dual antiplatelet therapy in preventing the occurrence of target vessel failure. Approximately 1400 patients will be enrolled at 17 centers in Korea. ${ }^{9}$

The CIBELES (non-acute Coronary occlusIon treated By EveroLimus-Eluting Stent) trial is an ongoing randomized study in Spain and Portugal comparing the EES and the sirolimus-eluting stent in 208 patients with chronic coronary occlusions. The primary endpoint is in-stent late loss at nine months. ${ }^{19}$

Other head-to-head trials evaluating the efficacy of the EES include BEST (1776 patients with multivessel disease comparing the EES with coronary artery bypass grafting in Korea), SORT-OUT (2678 patients, allcomers, comparing the EES and EES in Denmark), EXAMINATION (1500 patients with ST-segment elevation comparing the EES and BMS in Spain), TWENTE (1400 patients, allcomers, comparing the EES with the Endeavor ${ }^{\circledR}$ in The Netherlands), and XAMI (800 patients with ST-segment elevation comparing the EES with the sirolimus-eluting stent in The Netherlands). ${ }^{18,20}$

\section{Conclusion}

The EES has been demonstrated to be effective in reducing neointimal hyperplasia and restenosis in comparison with the BMS. Several head-to-head randomized trials have demonstrated consistently that the EES is more effective than the PES in reducing not only angiographic restenosis, but also cardiac events during follow-up. Some recent studies have shown a reduced risk of stent thrombosis at one year with the EES in comparison with the PES. Ongoing trials will provide more information about the efficacy of the EES in comparison with the SES. ${ }^{20,21}$

\section{Disclosure}

The authors report no conflicts of interest in this work.

\section{References}

1. Sheiban I, Villata G, Bollati M, et al. Next generation drug eluting stents in coronary artery disease: Focus on everolimus eluting stent (Xience V). Vasc Health Risk Manag. 2008;4:31-38.

2. Moreno R, Fernandez C, Sanchez-Recalde A, et al. Clinical impact of in stent late loss after drug eluting coronary stent implantation. Eur Heart J. 2007;28:1583-1591.

3. Farb A, John M, Acampado E, et al. Oral everolimus inhibits in-stent neointimal growth. Circulation. 2002;106:2379-2384.

4. Daemen J, Serruys P. Drug eluting stent update 2007. Part I: A survey of current and future generation drug eluting stents: Meaningful advances or more of the same? Circulation. 2007;116:316-328.

5. Windecker S, Juni P. The drug-eluting stent saga. Circulation. 2009;119:653-656.

6. Torguson R, Waksman R. Overview of the 2007 Food and Drug Administration circulatory system device panel meeting on the Xience $\mathrm{V}$ everolimus eluting coronary stent. Am J Cardiol. 2008;102:1624-1630.

7. Wiemer M, Seth A, Chandra P, et al. Systemic exposure of everolimus after stent implantation: A pharmacokinetic study. Am Heart J. 2008;156:751.e1-e7.

8. Tsuchiya Y, Lansky A, Costa R, et al. Effect of everolimus eluting stents in different vessel sizes (from the pooled FUTURE I and II trials). Am J Cardiol. 2006;98:464-469.

9. Ormiston JA, Serruys PW, Regar E, et al. A bioabsorbable everolimuseluting coronary stent system for patients with single de-novo coronary artery lesions (ABSORB): A prospective open-label trial. Lancet. 2008;371:899-907.

10. Stettler C, Wandel S, Allemann S, et al. Outcomes associated with drug-eluting and bare metal stents. Lancet. 2007;370:937-948.

11. Serruys PW, Ormiston JA, Onuma Y, et al. A bioabsorbable everolimuseluting coronary stent system (ABSORB): 2-year outcomes and results from multiple imaging methods. Lancet. 2009;373:897-910.

12. Stone G, Midei M, Newman W, et al. Randomized comparison of everolimus-eluting stent and paclitaxel-eluting stents. Two-year clinical follow-up from the clinical evaluation of the Xience V everolimus eluting coronary stent system in the treatment of patients with de novo native coronary artery lesion (SPIRIT) III trial. Circulation. 2009;119: 680-686.

13. Khattab A, Richardt G, Verin V, et al. Differentiated analysis of an everolimus-eluting stent and a paclitaxel-eluting stent among higher risk subgroups for restenosis: Results from the SPIRIT II trial. EuroIntervention. 2008;3:566-573.

14. Kedhi E, Joesoef KS, McFadden E, et al. Second-generation everolimus-eluting and paclitaxel-eluting stents in real-life practice (COMPARE): A randomised trial. Lancet. 2010;375:201-209.

15. Stone G. Everolimus elution from a durable polymer. Presented at the Transcatheter Cardiovascular Therapeutics meeting, Sep 21-25, San Francisco, CA, 2009.

16. Stone G. SPIRIT IV. A prospective, randomized trial comparing an everolimus-eluting stent and paclitaxel-eluting stent in patient with coronary artery disease. One year clinical results. Presented at the Transcatheter Cardiovascular Therapeutics meeting, Sep 21-25, San Francisco, CA, 2009.

17. Kastrati A. Clinical and angiographic results from a randomized trial of sirolimus-eluting and everolimus eluting stents: ISAR-TEST 4. Presented at the Transcatheter Cardiovascular Therapeutics meeting, Sep 21-25, San Francisco, CA, 2009.

18. Stone G. The XIENCE V/Promus everolimus-eluting stent: Comprehensive update of the clinical trial program. Featuring the first presentation of the SPIRIT III 3 year results. Presented at the Transcatheter Cardiovascular Therapeutics meeting, Sep 21-25, San Francisco, CA, 2009.

19. Park KW, Yoon JH, Kim JS, et al. Efficacy of Xience/Promus versus Cypher in reducing late loss after stenting (EXCELLENT) trial: Study design and rationale of a Korean multicenter prospective randomized trial. Am Heart J. 2009;157:811-817. 
20. Smits P, Ziekenhuis M, et al. Do everolimus-eluting or zotarolimuseluting stents offer advantages in STEMI? Presented at the Transcatheter Cardiovascular Therapeutics meeting. Sep 21-25, San Francisco, CA, 2009.
21. Rivero F, Moreno R, Barreales L, et al. Lower levels of in-stent late loss are not associated with the risk of stent thrombosis in patients receiving drug-eluting stents. EuroIntervention. 2008;4:124-132.

\section{Publish your work in this journal}

Medical Devices: Evidence and Research is an international, peerreviewed, open access journal that focuses on the evidence, technology, research, and expert opinion supporting the use and application of medical devices in the diagnosis, treatment and management of clinical conditions and physiological processes. The identification of novel devices and optimal use of existing devices which will lead to improved clinical outcomes and more effective patient management and safety is a key feature. The manuscript management system is completely online and includes a quick and fair peer-review system. Visit http://www. dovepress.com/testimonials.php to read real quotes from authors.

Submit your manuscript here: http://www.dovepress.com/medical-devices-evidence-and-research-journal 